\title{
Multiple forms of regulation and coordination across levels in educational settings
}

\author{
Sten Ludvigsen ${ }^{1} \cdot$ Ulrike Cress $^{2} \cdot{\text { Nancy } \text { Law }^{3}}^{*}$ \\ Gerry $\mathrm{Stahl}^{4} \cdot$ Carolyn P. Rosé $^{5}$
}

Published online: 13 April 2018

(C) International Society of the Learning Sciences, Inc. 2018

\section{Introduction}

All four papers in this issue of $i j C S C L$ problematize collaborative processes, as they play out differently depending on contextual factors. This problematization is related to three areas: 1) differences among the collaborating participants, who exhibit preferences and biases based on prior experience, 2) the variety of forms of small-group regulation, and 3) the ways collaboration plays out across activities and layers in the classroom.

There is a paradox in the analysis: We know that social interaction between multiple participants can facilitate shared understanding of the task and of task-related processes, and we know that this shared understanding is generally a necessary condition for accomplishing

Sten Ludvigsen

s.r.ludvigsen@iped.uio.no

Ulrike Cress

Ulrike@ijCSCL.org

Nancy Law

Nancy@ijCSCL.org

Gerry Stahl

Gerry@ijCSCL.org

Carolyn P. Rosé

cprose@cs.cmu.edu

1 University of Oslo, Oslo, Norway

2 Knowledge Media Research Center, Tübingen, Germany

3 University of Hong Kong, Hong Kong, China

4 Drexel University, Philadelphia, USA

5 Language Technologies Institute and HCI Institute, Carnegie Mellon University, Gates-Hillman Center 5415, 5000 Forbes Ave., Pittsburgh, PA 15213-3891, USA 
collaborative tasks. However, it is hard to characterize the formal and intentional settings that evoke such productive interactional processes. Why is it so tricky to analyze? The four papers in this issue shed light on this paradox.

\section{Collaboration and multi-touch tables}

Computer support for collaborative problem solving is a defining CSCL theme. The questions raised about this theme have varied depending on the type of computer support being investigated. In the study by Inga M. Bause, Trina R. Brick, Ann-Kathrin Wesslein, and Friedrich W. Hesse, participants use a collaboration-support kit to perform a task at a multi-touch table. The authors use a classical experimental design that is commonly used in social psychology - the so-called hidden-profile paradigm (SchulzHardt and Mojzisch 2012; Deiglmayr and Spada 2010) - to test how table-top features support information sharing.

Bause et al. emphasize in the paper that collaboration is involved in almost all workplaces, which means that we must coordinate and collaborate to accomplish work in the complex environments in which we are located. However, as the research in ijCSCL has shown, not all conditions and tools lead to productive and efficient collaboration. One of the most important problems with computer support in collaborative settings is fostering mutual understanding, which is variously labeled common knowledge, common ground, inter-subjectivity, and shared understanding, to name a few relevant concepts. The underlying rationale is obvious, but not trivial: if participants do not agree on the framing and direction of the problem solving, they cannot even communicate effectively. Using a multi-touch table can improve collaboration, because the external representations support participants' reasoning processes by making them visible and shared, thereby facilitating joint thinking.

The Bause et al. study uses as its analytic stance the PISA framework, which emphasizes the relevance of establishing and maintaining shared understanding for collaborative problem solving. The study tests if a collaboration tool kit that comprises joint and private table-top spaces would support collaboration by reducing biases from individual preferences or from the discussion process. In detail, the study observes discussion intensity and discussion bias at the group level and information-processing intensity and evaluation bias at the individual level. The study includes 54 triads of university students from different fields of knowledge.

The study's results show that the collaboration kit helped to overcome previous preferences and discussion biases. The group that worked with these kits outperformed the others and showed less biased communication and more collaborative processes. Those in the treatment group were able to adjust their use of task-relevant interaction processes. This result is in line with the results of a number of studies using multi-touch tables (Higgins et al. 2011; 2012). Cress et al. (2011) found the provision of such private and shared spaces on a multi-touch table can even support the collaboration of pupils with mental disabilities.

The Bause et al. study makes an important contribution to CSCL research by providing insights into collaborative problem-solving at a rather fine-grained level. The PISA framework (OECD 2017) may be used to scaffold CSCL research, as it provides a clear conceptual framework for the processes that have to be considered. This may help us to understand the differences among various forms of computer support in order to explain the conditions under which computational support may be beneficial, for what, and in which ways. 


\section{Various forms of regulation}

Forms of regulation are a central issue in CSCL. Regulation can be supported by the computational tool itself, by the individual, or by social interaction (see Järvelä et al. 2016, for a recent overview). You Su, Yanyan Li, Hening Hu, and Carolyn P. Rosé explored self- and social-regulation of college students studying English as a Second Language (ESL) during wiki-supported collaborative reading activities. The 16-week study included 60 Chinese college students who worked in groups. While various forms of regulation have been studied in many domains in CSCL, less attention has been paid to regulation among students learning a second language. Most often, regulation has been conceptualized as self-regulation and the individual has been the unit of analysis. Su et al. take a different stance, advocating the need to study regulation processes using the inter-personal level as the starting point and focusing on the interdependency between individual action and social context. Recent regulation research has included analysis of self-regulation, co-regulation, and social regulation (Järvelä et al. 2016). Analysis on all three of these levels is also the aim of the Su et al. study.

The study's empirical context is a wiki-environment in which the students engaged in "literature circles," which are peer-led reading groups that aim to enhance students' literacy skills. Each student is assigned a specific role in his or her group and was encouraged to share ideas, feelings, questions, connections, and judgements about the texts used.

The main source of content for the sequential analysis was data from the chat log. Su et al. used three different coding schemes for data analysis: coding for social intentionality; coding for processes, including planning, monitoring, regulating, and evaluating; and coding for emotions, task dimensions, and the organization of the activities. The results show that students are able to participate in groups and engage in social regulation, but that they struggle with content regulation. The high-performing group was able to participate in content regulation through cognitive activities, including checking, elaborating on, revising, and improving the responses of other group members. In the regulation literature, content regulation is viewed as the main indication of more advanced cognitive performance. The study confirms this finding in the area of second-language learning. The high-performing group had more advanced bidirectional patterns between different forms of regulation. The low-performing group used only self-regulation when working with the content. In addition, the highperforming group was able to regulate and change its action as part of organizing the activities, including monitoring the process and content, while the low-performing group was more repetitive in its actions and did not change its way of organizing its work. The results from this study extend previous CSCL research in this area and provide designers and teachers with new insight into how the environment can support students' work and into the ways in which teachers may need to intervene in student groups to make sure that they engage in advanced cognitive activities (Furberg 2016).

In a second paper also focusing on regulation, the study by Marcela Borge, Yann Shiou Ong, and Carolyn P. Rosé provides new insights into the understanding of group regulation. In their paper, "Learning to monitor and regulate collective thinking processes," they propose a framework to help students improve collaborative knowledge-building processes in small groups. This framework builds on two principles. The first is that the individual work that students do needs to become part of their collaborative work and to be synthesized as they develop shared meaning. This means that the students need to identify whether there are any substantial differences among them regarding how they solve a task. Many CSCL studies have shown that this is a serious challenge because cognitive differences and socio-emotional stress 
are identified as major elements in many collaborative efforts. The second principle is that the collective knowledge produced needs to be negotiated through communication processes. This study assumes that communication patterns will affect how participants involve themselves in the collaboration. Communication patterns activate specific forms of collaboration and cognition. While other studies have focused mostly on awareness and planning, Borge et al. focus on how regulation plays out in activities over time.

Thirty-seven university students who were taking an introductory class in information sciences and technology participated in this 16-week study. The design of the environment involved students' use of rubrics to score how their group worked together. The rubric scores were also used in small-group discussions. Participants were grouped into two conditions: future-thinking and evidence-based. Students in the future-thinking condition were asked to score each micro-communication pattern and provide the group with a strategy to improve one aspect of the process in the next session. Students in the evidence-based condition were asked to score each micro-communication pattern and provide evidence from the session to support their own score. In other words, the future-thinking participants were asked to focus on improving their knowledge of socio-metacognitive strategies, and the evidence-based ones were asked to focus on the existing communication processes. These two conditions should be viewed as ways of scripting the students' collaborative efforts.

The study's results show that these scripts influence students' collaborative efforts over time. The evidence-based conditions helped students to develop their capacity to see collaborative processes as products of their own thinking that can be improved upon. This improvement is dependent on socio-metacognitive sense making, and plays out as part of the regulatory processes. The study shows that more high-quality discussion took place in the groups using the evidence-based condition. Borge et al. emphasize that in this condition students had to pay attention to identify how group members differ in their contributions. This stimulated regulatory processes for themselves and for the entire group. So, similar to the other studies in this issue, this study corroborates the finding that the establishment and maintenance of common ground is a necessary condition for solving a problem collaboratively (Järvelä et al. 2016).

\section{Individual actions, group processes and collective activities in the classroom}

A core focus in studying CSCL from a socio-cultural stance is the idea of analyzing how actions, group processes and collective activities in the classroom are interwoven and mediate each other. Collaborative learning is constituted through actions and activities that are dependent upon (a) the actors' own knowledge and learning trajectories; (b) their interaction with each other and the social setting, which introduces both historical elements and current/future challenges. An example of a historical element is the specific organization of a knowledge domain. An example of a current/future challenge is the use of software as a resource for the students and the teacher. Tobin White's study of connecting levels of activity with classroom network technology contributes a theoretical and methodological stance and robust empirical analysis of students' and teachers' learning processes in the domain of mathematics. The study uses an experimental design to test specific resources for improving students' learning. White addresses how students solve mathematical problems by using digital tools: Terms and Operations, which are used with polynomial expressions; and Graphing in Groups, which enables joint manipulation of linear functions. 
White analyzes how the connected levels play out in the classroom. In CSCL studies, a number of authors have addressed the issue of multiple levels or planes (Damsa 2014; Furberg et al. 2013; Furberg 2016; Ludvigsen and Arnseth 2017; Stahl 2013a; Arnseth and Krange 2016), and this issue has also been a theme in editorials (Stahl 2012, 2013b; Stahl et al. 2014). Connecting levels in the socio-cultural stance originates with the idea that human development and learning are based on the interdependencies among microgenesis, ontogenesis, and sociogenesis. Rogoff (1995) labeled these as personal, interpersonal, and institutional planes of analysis, implying that an empirical analysis may focus on one plane, but it does so with the understanding that actions emerge as parts of interrelated planes. It is important to note that the three interdependent layers have analytic distinctions that we can use to perform a differentiated analysis of social practices. Some of the key concepts used in analysis - including mediation, appropriation and emergence - have the potential to be used across levels. When students express themselves in a domain, their utterances become part of the collaboration and can be transformed into resources for the institutional activity.

Historically, classrooms have been connected to knowledge through textbooks. Today, digital infrastructures and representational technologies connect students and teachers to multiple worlds and forms of knowledge, making the connection between levels more complex than before, but increasing the opportunities for students to share and participate simultaneously in classroom activities. This increased complexity of the connection between levels makes the classroom more complex for both students and teachers.

White's study contributes to the CSCL field by shedding light on how students learn and what they learn in complex ecosystems that include digital infrastructures and tools, and about collaborative efforts in an institutional setting. The interdependencies among the three levels are integral to the conditions for student learning.

\section{The squib - one framework to rule them all?}

In the squib, associate editor Nikol Rummel takes a stance about the status of the eight provocations for the field put forth by Wise and Schwarz (2017). She argues that though they emphasize different important dimensions in the CSCL field, they don't really develop a new position that could serve as common premises for the field. Accordingly, Rummel argues and presents a taxonomy that could serve as framework for CSCL work in the future. The taxonomy is an interesting contribution to the ongoing discussion about how to improve CSCL research by developing opportunities for a shared agenda.

\section{References}

Arnseth, H. C., \& Krange, I. (2016). What happens when you push the button? Analyzing the functional dynamics of concept development in computer supported science inquiry. International Journal of Computer-Supported Collaborative Learning, 11(4), 479-502.

Cress, U., Wodzicki, K., Bientzle, M., \& Lingnau, A. (2011). CSCL for intellectually disabled pupils: Stimulating interaction by using a floor control mechanism. International Journal of Computer-Supported Collaborative Learning, 6(2), 307-321.

Damsa, C. I. (2014). The multi-layered nature of small-group learning: Productive interactions in objectoriented collaboration. International Journal of Computer-Supported Collaborative Learning, 9(3), $247-281$. 
Deiglmayr, A., \& Spada, H. (2010). Collaborative problem-solving with distributed information: The role of 944 inferences from interdependent information. Group Processes \& Intergroup Relations, 13(3), 361-378. doi: https://doi.org/10.1177/1368430209342259.946

Furberg, A. (2016). Teacher support in computer-supported lab work: Bridging the gap between lab experiments and students' conceptual understanding. International Journal of Computer-Supported Collaborative Learning, 11(1), 89-113.

Furberg, A., Kluge, A., \& Ludvigsen, S. (2013). Student sensemaking with science diagrams in a computerbased setting. International Journal of Computer-Supported Collaborative Learning, 8(1), 41-64.

Higgins, S., Mercier, E., Burd, L., \& Joyce-Gibbons, A. (2012). Multi-touch tables and collaborative learning. British Journal of Educational Technology, 43(6), 1041-1054.

Higgins, S. E., Mercier, E., Burd, E., \& Hatch, A. (2011). Multi-touch tables and the relationship with collaborative classroom pedagogies: A synthetic review. International Journal of Computer-Supported Collaborative Learning, 6(4), 515-538.

Järvelä, S., Kirschner, P. A., Hadwin, A., Järvenoja, H., Malmberg, J., Miller, M., \& Laru, J. (2016). Socially shared regulation of learning in CSCL: Understanding and prompting individual- and group-level shared regulatory activities. International Journal of Computer-Supported Collaborative Learning, 11(3), 263-280. https://doi.org/10.1007/s11412-016-9238-2.

Ludvigsen, S., \& Arnseth, H. C. (2017). Computer-supported collaborative learning. In E. Duval, M. Sharples, \& R. Sutherland (Eds.), Technology enhanced learning (pp. 47-58). Chicago: Springer International Publishing, Computer-Supported Collaborative Learning.

Organization for Economic Cooperation and Development. (2017). Pisa 2015 collaborative problem solving framework. Retrieved from https://www.oecd.org/pisa/pisaproducts/pisa2015draftframeworks.htm.

Rogoff, B. (1995). Observing sociocultural activity on three planes: Participatory appropriation, guided participation, and apprenticeship. In J. V. Wertsch, P. del Rio, \& A. Alvarez (Eds.), Sociocultural studies of mind (pp. 139-164). Cambridge: Cambridge University Press.

Schulz-Hardt, S., \& Mojzisch, A. (2012). How to achieve synergy in group decision making: Lessons to be 1065 learned from the hidden profile paradigm. European Review of Social Psychology, 23(1), 305-343. 1066. https://doi.org/10.1080/10463283.2012.744440.

Stahl, G. (2012). Traversing planes of learning. International Journal of Computer-Supported Collaborative Learning, 7(4), 467-473.

Stahl, G. (2013a). Translating Euclid: Designing a human-centered mathematics. San Rafael: Morgan \& Claypool Publishers.

Stahl, G. (2013b). Learning across levels. International Journal of Computer-Supported Collaborative Learning, $8(1), 1-12$.

Stahl, G., Ludvigsen, S., Law, N., \& Cress, U. (2014). CSCL artifacts. International Journal of ComputerSupported Collaborative Learning, 9, 237-245.

Wise, A.F. \& Schwarzm B.B. (20017). Visions of CSCL: eight provocations for the future of the field. International Journal of Computer-Supported Collborative Learning, 12(4), 423-467. 